\title{
Peculiarities of Consumer Behavior Management of Young People in a Metropolis-World Experience
}

\author{
Mihail Nikolaevich Dudin ${ }^{1}$, Nikolaj Vasil'evich Lyasnikov ${ }^{1}$, Katrina Benikovna Dobrova ${ }^{2}$, Nataliya Vladimirovna \\ Vysotskaya $^{3} \&$ Evgeny Danilovich Katulsky ${ }^{4}$ \\ ${ }^{1}$ Russian Academy of Entrepreneurship, Russian Federation \\ ${ }^{2}$ Moscow Aviation Institute (National Research University), Russian Federation \\ ${ }^{3}$ Moscow City Government University of Management in Moscow, Russian Federation \\ ${ }^{4}$ Modern University for the Humanities, Russian Federation \\ Correspondence: Mihail Nikolaevich Dudin, Radio str. 14, Moscow, 105005, Russian Federation. E-mail: \\ dudinmn@mail.ru
}

Received: June 17, 2014 Accepted: July 30, 2014 Online Published: September 28, 2014

doi:10.5539/ass.v10n20p38

URL: http://dx.doi.org/10.5539/ass.v10n20p38

\begin{abstract}
The aim of this work is to detect and identify peculiarities of consumer behavior management of young people with regard to their residence in metropolis areas and regions geographically remote from cultural and geographical centers. Within the framework of the work, theoretical, methodological, and empirical research on the announced topic are carried out through an interdisciplinary approach. As part of the work, the following main conclusions were obtained:

- Consumer behavior is an area of scientific and practical research. We consider world consumer behavior in the context of a particular community of systematic components that reflect in an integrated manner a relationship between the demand for tangible and/or intangible goods of individuals in meeting their own needs and all other relevant factors which characterize the selection of goods from the rational or the emotional point of view;

- Consumer behavior can be considered as a process as well. In this case, consumer behavior is a sequential formation of a set of needs in tangible and/or intangible benefits by individuals. In the same process methods, forms and mechanisms are formed for meeting these needs by offering to the market a set of authentic goods corresponding to the needs, goods are characterized by certain quantitative and qualitative characteristics and the level of availability for a specific consumer;

- Consumer behavior is determined by some factors that are differentiated, as a rule, as factors of the external and internal environment. External factors are socioeconomic determinants; internal factors are determinants of motivation, stimuli for consumption and later are specified from the position of the consumer as a subject or an object (private or corporate consumption). The private mass or individual consumption and the national cultural characteristics or the mentality of consumption are at the forefront and of the greatest interest;

- We associate the mentality of consumer behavior with the epitome in the consumption pattern of some stable combination of views, values, norms of behavior and moral norms, which are characteristic for a life of a particular group of people. Consumer behavior can vary from group to group in the same socio-cultural (territorial) or national community, as well as in different socio-cultural (regional) or national communities;

- Consumer behavior of young people, who live in metropolitan areas and regions that are geographically remote from the center, is characterized by considerable differentiation. We discovered that the consumer behavior of youth in metropolises on the one hand is influenced by common factors and environmental determinants, but on the other hand, formation of consumer behavior of young people is based on the use of extended screening opinion leaders, at the same time the consumer behavior of youth of metropolises is characterized by sufficient assertiveness, but by desire for innovativeness and goods consumption that have value characteristics.
\end{abstract}

Keywords: consumer, consumer behavior, youth, youth of metropolises and peripherals, consumer behavior management 


\section{Introduction}

Changes in political, economic, social and other macro-trends in the last two decades had an impact on consumer behavior of the population and individuals. Consumer behavior as a subject area of research is almost always considered in an interdisciplinary perspective. It is more than justified, as it is hardly possible to find areas of life of modern society, which are not directly or indirectly related to the needs of individuals and their behavior. From the interdisciplinary perspective consumer behavior is usually considered in philosophical, sociological, economic and psychological contexts.

The primary context in considering the essence and aspects of consumer behavior is the philosophical context (Bogatyreva, 2011). Many studies of the philosophical context considered by us and on our topic indicated that consumer behavior, more accurately ancient ideas about it, was the basis for the modern game theory. Therefore, from a philosophical point of view (in simplified representation) consumer behavior is a game between market agents (consumers and producers of tangible and intangible goods, and their intermediaries). This game can last indefinitely until the objectives of all participating agents are not achieved. The game may be terminated if the purpose of interacting agents is not achieved at all.

Given that a priori objectives are formalized expression of the needs, and requirements do not have the final quantitative or qualitative values, i.e. tend to grow faster, respectively in the philosophical context of the game theory consumer behavior can be considered as a self-sustaining and self-organizing system construct. Further philosophical concepts considered consumer behavior as a role social game, based on the fact that consumption is not only a physiological comfort, but the condition of differentiating provisions of some consumers against other consumers (status of consumption, ability to meet not only the vital needs of the individual body, but also its combination with needs of a soul). It is obvious that in this case philosophical context of the considered topic has common grounds with sociology and psychology.

In sociology modern society is seen as a consumer society (Baudrillard, 2000). From the point of view of sociology the basis for functioning and development of the society is consumption, consumption is the mechanism of social inclusion of the individual. In the sociological context consumer behavior is seen through the prism of the public (social) stratification, where the roles of individuals in society are determined by their status, and their status in turn determines types, forms and volumes of goods consumption. Considerable attention in sociology is paid to manipulating mass consciousness as well, i.e. motivating and stimulating consumer behavior. On those grounds, the sociological context of consumer behavior is associated with economic and psychological context.

In the economic context, consumer behavior is usually reconsidered, first, in terms of rationalization (the individual desire to maximize utility) (Kovalchuk \& Tarhanova, 2005) and second, in terms of institutionalization (individual inclusion in various kinds of commodity-monetary or economic relations). Thus, in the economic context consumer behavior is described on the one hand as a set of terms defining actions of a specific individual aimed at meeting (the most efficient) of his own needs. On the other hand, given the institutionalization, consumer behavior is a consequence of the impact of the set of environmental determinants on inner interest of the individual and its potential ability to meet his own needs. Taking into account that the needs of the individual are almost unlimited (except for the ability to satisfy them), and the individual's own views on the process of consumption is a relational paradigm of economics, respectively under this economic context of consumption is correlated with the psychological context (Baudrillard, 2000).

In psychology, consumer behavior patterns are studied through the prism of the relationship of the individual (Leibenstein, 1995) with the product of consumption (goods, work, services). For the psychological context of consumer behavior the primary reactions are mental emotional or rational ones (Moscovichi, 1998), (Kovalchuk \& Tarhanova, 2005) to external stimuli, which may both promote and inhibit the formation of the individual's abilities to meet his own needs. In psychology consumption (as an object of research and as a process) is associated with economic and social behavior of the individual, for each of these types of behavior the three components are characteristic ones (affective/emotional, cognitive/rational, motivational and volitional). Through complementary action of these components, the individual, as a rule, makes a decision concerning forms and methods to meet the needs. In other words, the psychological context of consumer behavior considers a mechanism of selection a certain tangible and/or intangible goods by the individual in the current institutionalized conditions and under the influence of inner motivation as a response to environmental stimuli (Bogatyreva, 2011). So, having considered the set of interdisciplinary contexts formalizing the essence of the concept of consumer behavior, it is necessary to submit its theoretical content. Consumer behavior as a field of scientific and practical research is a specific systematic commonality of components that reflect in an integrated 
manner relationship between the demand for tangible and/or intangible goods of individuals in meeting their own needs and all other relevant factors, which characterize a choice of goods from the rational or emotional point of view.

\section{Methods}

In methodological terms, this article is an interdisciplinary research in socio-psychological and economic-philosophical. The study of methodological framework of consumer behavior allows concluding that the primary objective is the needs of the individual, which determine his motives, and the reaction of internal consumer motivation to stimuli and external determinants (Dudin et al., 2013a). As the main methodological models describing the specifics of consumer behavior, including consumer behavior of young people living in metropolitan areas, in this paper we took the following models: functional demand, distancing, conspicuous consumption and the qualitative demand. It should be noted that the overall methodological basis of all these models is based on the assumption of the level of consumer involvement into the selection process of a product, as well as into differentiating goods themselves (Istratov \& Eksausto, 2010). It should be understood that depending on the comparison of the level of involvement of the consumer into the process of product selection and key characteristics of the latter, there are four consumer types of customers' behavior:

- The first type. Complex consumer behavior, which takes place at a high degree of involvement in the selection of goods and a significant differentiation in a retail offer of a homogeneous product group. Selection of a particular good is usually associated with sufficiently high consumer risks, which are formed due to differences in functionality, reliability and quality of goods a homogeneous group. High involvement takes place when choosing status goods, durables goods, good purchased for the first time (Petrovsky \& Yaroshevskii, 2010) and etc.;

- The second type. Unconfident consumer behavior also takes place at a high involvement of the buyer in the selection of the goods, but at the same time, product differentiation within a homogeneous group of products will be very small or relatively small. In this case, consumer risks of choice are reduced, but the level of consumer doubts in choosing the right product is high;

- The third type. In exploratory consumer behavior the degree of involvement of consumers in the selection of commodity products is insignificant, but product differentiation within a homogeneous group of products is quite high. Generally, low level of involvement in the selection of goods takes place when choosing products of FMCG (Fast Moving Consumer Goods). Consumer risks in this case are low, but the consumer uses the opportunity to expand his choice;

- The fourth type. In habitual consumer behavior, the degree of the involvement of consumers in the selection of goods is low, and the differentiation between products within a homogeneous group of products is insignificant. Risks of consumer selection in this case are completely absent, the specificity of consumer behavior is stereotyped, and the consumer does not need to expand the selection.

Thus, the methodological aspect of the study of consumer behavior, including consumer behavior of young people living in metropolises, is a multidisciplinary research based on the idea of the four traditional types of behavior types and models of consumer behavior and consumer selection derived from them.

Taking into account the main points outlined in the "Introduction" of this article, consumer behavior can be seen as a process that represents the sequential formation of a set of needs in tangible and/or intangible goods by individuals. In the same process methods, forms and mechanisms are formed for meeting these needs by offering to the market a set of authentic goods corresponding to the needs, goods are characterized by certain quantitative and qualitative characteristics and the level of availability for a specific consumer;

From the definitions outlined in the "Introduction" we can conclude that Consumer behavior is determined by some factors that are differentiated, as a rule, as factors of the external and internal environment. External factors are socio-economic determinants, which as a rule are specified in the four main aspects: the actual social, strictly economic, cultural and political, scientific and technological. It is absolutely clear that internal factors are determinants of motivation, stimuli for consumption and later are specified from the position of the consumer as a subject or an object (private or corporate consumption). In this case, we are interested in the private mass or individual consumption, and here the national cultural characteristics or the mentality of consumption is at the forefront (Filyurin, 2010), which manifests itself in behavior of young people living in a metropolises (in particular in Russian largest cities-Moscow and St. Petersburg, as well as in other major cities around the world).

\section{Results}

The recent data shows that consumer behavior of certain social groups is characterized by a regular change in 
which you can highlight certain key trends. In particular, ongoing international research objectively proves that leading Chinese growth observed in the last decade stimulates a transformation of consumer demand. It is predicted that within a year the Chinese consumer market will generate about $40 \%$ of the global luxury goods market, at the same time the most active consumption of luxury products is among the youth segment (see Figure $1)$.
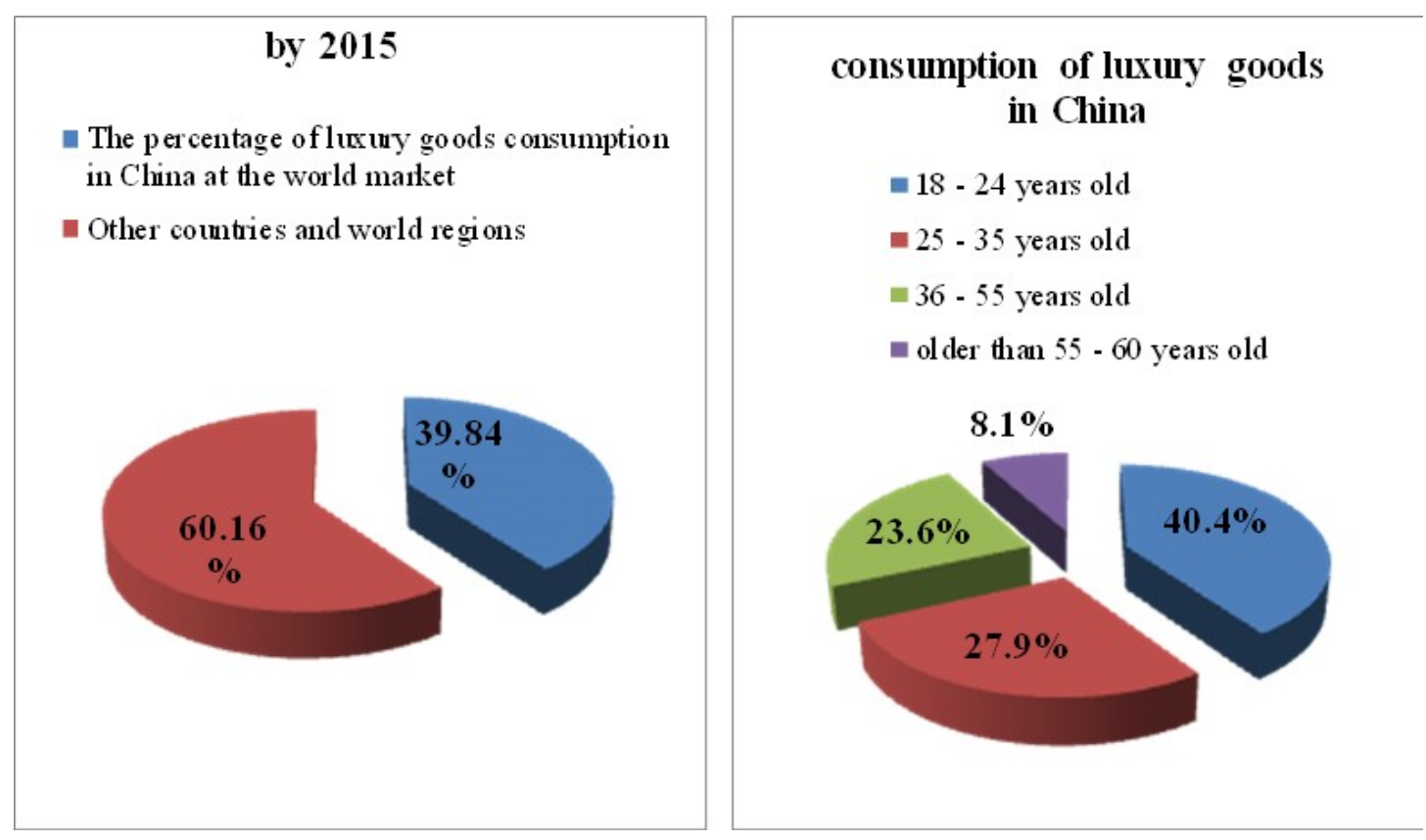

Figure 1. Statistics of luxury goods consumption in China (Roland Berger SC, 2012)

Consumer behavior in China on the one hand is characterized by asceticism and hedonism. Asceticism is characteristic for older age groups, hedonism of consumption is very pronounced among young people. The demographic differences of consumption will be discussed in section "Discussion", here we will note that there is an objective variability of consumer behavior which is largely determined by national and socio-cultural characteristics of consumption of tangible and intangible goods. For example, considering the European (Constantinescu, Goldbach, \& Gavrila, 2009), American (Luna \& Gupta, 2011) and East Asian (Ibrich, 2013) ethno-cultural model of consumer behavior, it is necessary to allocate in them the general and the particular. Behavior of European and American consumers is considered the most predictable in terms of forecasting motivational reactions to external stimuli. European consumer behavior is characterized by the following features:

1) desire to preserve consumption traditions while increasing interest to innovative products and to new forms of market interaction of agents acting on the side of demand and on the side of consumption

2) predominance of tangible consumption over intangible consumption

3) hedonism of consumption and postmodern trends, showing the convergence of mass and elite consumption

In behavior of consumer geographically located in the U.S., we can single out the following features:

1) presence of cross-cultural trends and intolerance to manifestations of specificity of meeting the needs of certain social (local) groups/strata;

2) reutilization and network process consumption, high innovative consumer susceptibility;

3) hedonism of consumption with distinctively postmodern trends.

Obviously, consumer behavior in Europe and the United States is characterized by a certain similarity. Moreover, in recent years, transformation of consumer behavior is objectively identified in terms of social and environmental responsibility (new type of consumerism-green responsible consumption, rationalization of consumption: rejection of excess consumption). East Asian (Japanese and Chinese) national model of consumer behavior has always been different from the European and the American ones (Ibrich, 2013): 
1) the biggest manifestation of the quality and brand dependency in consumption. In Japan as well as in China, the luxury market is more developed than in other countries;

2) patriotism and self-sufficiency-orientation mainly for domestic products in consumption. Patriotic consumption is not always the case in China;

3) relative balance of consumption of tangible and intangible goods-mainly in Japan;

4) active combination of respect for national traditions and high innovativeness.

In the Japanese consumer tradition converged globalist tendencies also began to appear over the past few years, these tendencies can also be described as follows (Ibrich, 2013):

1) refocusing in consumption: previously the principle "spend money to save time" functioned, now the principle of "spend time to save money" functions;

2) change in the concept and method of consumption: physical shopping prevailed previously, now the virtual (online) shopping dominates;

3) change in consumer responsibility: environmentally oriented hedonism prevailed previously in consumption, now asceticism of consumption oriented for eco-friendly and anthropo-safe production increasingly is observed more often.

In turn, the socio-cultural consumption in the exogenous aspect may be due to the following determinants:

1) social stratification and remoteness of groups/strata from each other (it determines the speed of transition of consumers from one group/stratum to another (Giddens, 1986) and hence a kind of consumer behavior model);

2) consumer confidence in the future (this determines the inclination of individuals to consume goods or to accumulate necessary resources, which can be further used to meet the needs);

3) gender consumer characteristics (it determines the type of consumer behavior in terms of masculinity and femininity);

4) basic consumer principles: individual or collective (it determines the structure of consumption or consumer balance of public and private goods).

Consumer behavior in terms of its managing is characterized by dynamism, determinism, reactivity and in some cases by stochasticity. Characteristics of consumer behavior can be modified under the influence of combined external and internal factors, among which national and territorial factors play quite a significant role, which in turn correlates with the highest social stratification and the current demographic situation.

\section{Discussion}

Consumer behavior is usually studied in several basic models, which are derived from the actual effects of behavior:

1) the model of functional demand, which is based on the fact the purchase of any product is strictly aimed at meeting the arisen need. This model reflects the rational behavior of an "economic man";

2) the model of merging (the "common carriage" effect). This model is based on the fact that the product is not acquired by virtue of objective necessity (the arisen need), but due to manipulation and stimulation of mass consumer awareness;

3) the distancing model ("snob effect" (Leibenstein, 1995)). This model is based on the fact that the consumer purchases a product unavailable to others and refuses to purchase affordable products;

4) the model of conspicuous consumption ("Veblen effect"). The model is based on the consumption of exceptional goods that are not available for the majority of population because of the high cost of these goods;

5) the qualitative model. In this model, consumption is based on the desire to either achieve the perfect balance "price-quality" or the desire to acquire the product of only one brand that is associated with high quality. In the latter case, the model can be considered as brand dependency.

With this in mind, we distinguish two major basic fundamentals of consumer behavior:

1) the kind of rational consumer behavior, where the consumer wants to maximize their benefits. At the same time the consumer almost always knows in advance what choice he will make and why, hence the rational consumer behavior according to the level of control is rather complicated, but predictable and sustainable to the influence of market factors and incentives; 
2) the kind of irrational consumer behavior, where the consumer on the one hand wants to maximize his benefits, on the other hand he is so prone to influencing factors (stimuli), mainly coming from the external environment, that his behavior is sufficiently manageable (note that this kind of consumer behavior very beneficial for all kinds of sales and other marketing actions). However, the behavior of the consumer is difficult to predict, and therefore unstable, prone to the influence (a situation changes-behavior changes).

Based on the above said we can note that the essence of consumer behavior management, including consumer behavior of young people living in a metropolis, comes down not only to merely seek effective stimuli in line with internal motives of the consumer, but first of all effective management of consumer behavior will take place only when external stimuli will be formed taking into account a type, a form and a pattern of behavior in a particular consumer group.

Considering the demographic aspect of consumer behavior, we deem it necessary to take a closer look at the peculiarities of this behavior of youth in a metropolis. It is known a priori that a metropolis as a highly urbanized socio-economic system, is characterized by a high pace of the city life, fast changes of fashion consumer trends, high availability of goods, works and services, as well as the sources for acquiring them (purchasing). Young people, as the most active consumer group, is prone to changes of consumer stereotypes, changes of traditions of organizing personal and public space, high susceptibility to innovations, transformation of traditionalist attitudes, reduction of pre-existing gender differences in consumption. The major determinants of youth consumer behavior are:

1) geographical location. Remoteness of residence of youth social groups from the cultural and geographical centers imposes a significant imprint on the model of consumer behavior that can be expressed in a slow and fairly predictable change in consumer mood, entrenched values of consumer mentality, despite the processes of globalization and urbanization;

2) personal values. A central component of this determinant-personal identity (Chalmers, 2013), which on the one hand provides continuity of self-perception to the younger generation. On the other hand it realizes through a couple of opposites: the unity of the constancy and variability (Castells, 2007; Habermas, 1971), which makes youth the most open to new perceptions and organically tending to consume new;

3) lifestyle. Lifestyle of young people in a metropolis erases national consumer traditions, determining that the primary choice of the individual is personal, formed not by "the bandwagon effect ", but by an opinion leader (socially active actor (Castells, 2007), who is able to affect the perception of the surrounding reality by young people and transform it by these means, including the model of consumer behavior).

Web can single out several major differences that characterize consumer behavior of youth in metropolises and in geographically remote from the centers of cultural and geographical regions (see Table 1).

Table 1. Peculiarities of consumer behavior of young people in a metropolis and in geographically remote regions (compiled by the author)

\begin{tabular}{ll}
\hline Youth in metropolises & Youth in geographically remote regions \\
\hline Youth values & Family, patriarchy \\
Education (career) & The desire to migrate higher social strata \\
Promotion at the social/corporate ladder (status) & Innovativeness in organizing life and meeting \\
the needs & Traditionalism in organizing life and meeting the needs
\end{tabular}

Youth consumer choices and behavior models

The relative balance in the consumption of tangible and intangible goods

High prevalence of material consumption, intangible consumption is often not perceived as needed or objectively necessary

Rational brand dependency and quality Irrational brand dependency and quality orientation
orientation

Convergence of mass and elite consumption

Mass network process with the formation of the Institute of opinion leaders and followers

Divergence of mass and elite consumption

Frequent and multiple manifestations of the effects of "common carriage," Veblen, distancing 
Obviously, youth consumer choice and the corresponding model of consumer behavior is influenced by personal values, which are characterized by significant differences in young people living in metropolitan areas and young people living in geographically remote from the centers of cultural and geographical regions. Consumer behavior management of young people, which is based on the above features, should take into account that the consumer behavior of youth in metropolises additionally has the following specific features (Dudin \& Lyasnikov, 2012):

1) active acquisition of status skills that are based on a fairly high intellectual abilities and caused by a change of social stereotypes (the emergence of a qualitatively new youth class corresponding to the features of life in the information society);

2) the pursuit of healthy lifestyles (food culture, culture of physical development, appearance culture) and spiritual development, also expressed through the formation of active citizenship (or opposition of individual youth groups);

3) desire to organize leisure activities with the massive use of quality service of the entertainment industry, integration of entertaining and informative activities;

4) formation of rational brand dependency is expressed in purchasing goods and services attributable to the category of "necessary luxury" (Dudin, Ljasnikov, Kuznecov, \& Fedorova, 2013).

It should be noted that the existing difference between youth of metropolises and youth of geographically remote regions determines the choice of tools for managing their consumer behavior (see Table 2 below).

Table 2. Peculiarities of consumer behavior management of youth in metropolises and youth in geographically remote regions (Compiled by the author)

\begin{tabular}{ll}
\hline $\begin{array}{l}\text { Youth of megapolises (Moscow, St. Petersburg, and } \\
\text { other world cities) }\end{array}$ & Youth of geographically remote regions \\
\hline $\begin{array}{l}\text { Influence on consumers through values } \\
\text { Selective, direct interaction with the consumer in mass } \\
\text { advertising support }\end{array}$ & Active use of massive indirect advertising \\
$\begin{array}{l}\text { The use of the construct "an opinion leader } \rightarrow \\
\text { followers" for shaping consumer choice motivation }\end{array}$ & $\begin{array}{l}\text { The use of close reference groups (family, friends) for } \\
\text { shaping consumer choice motivation }\end{array}$ \\
$\begin{array}{l}\text { Pre-emptive use of feedback and non-price (value) } \\
\text { methods to stimulate consumer demand }\end{array}$ & $\begin{array}{l}\text { Pre-emptive use of price (dumping) methods to } \\
\text { stimulate consumer demand }\end{array}$ \\
\hline
\end{tabular}

Obviously, youth consumer behavior in a metropolis I influenced to a lesser extent by national traditional values, but formed primarily under the influence of personal values and personal identity.

Therefore, consumer behavior management of youth in a metropolis and youth living in geographically remote from the cultural and geographical centers regions will be based on a set of qualitatively different methods. In particular, for managing consumer behavior of young people living in geographically remote areas form the center more traditional marketing methods are acceptable, the use of which is aimed more at maximizing volumes of goods consumption using current price offers. Methods of formation of consumer loyalty and consumer securing using value but not price characteristics of the product is more typical for managing consumer behavior of young people living in a metropolis. We should pay attention to the fact that the methods of viral exposure (exposure based on reference groups) for consumer behavior of youth of metropolises and youth living in geographically remote from the geographic center regions will also vary dramatically. For example, young people who live in geographically remote regions will be motivated to a greater extent to choose certain goods according to an opinion of their entourage. This opinion, due to the fact that it is represented by a limited reference group, is deeply subjective and does not reflect real quality, value and price characteristics of selected products. In contrast, youth of metropolises, using opinion screening of a variety of reference groups and opinion leaders, form their motivation for selection of goods (as well as works and services) based on more objective attitudes that characterize the true value, cost and quality of selected products. It is also worth mentioning that the expanded opinions screening and reviews of other consumers at a high level of assertiveness of consumer behavior of youth in metropolises constitutes the theoretical and methodological basis for the development of management concepts of such behavior. On the one hand, it complicates consumer behavior management techniques that can be applied to youth of metropolises, but, on the other hand, allows us to create effective channels and multidimensional stimuli of influencing on volumes of goods consumption by youth in 
metropolises already not through direct interaction with this consumer group, but through indirect influence on the opinion and consumer behavior of opinion leaders.

\section{Conclusions}

Summarizing this article, it should be noted that consumer behavior management will be a purposeful process. As part of this process not only the structure of the needs of a social group (strata) is studied, but also its behavior determinants, and a list of decisions is formed to ensure effective stimulating effect on the motivation to meet the needs considering cultural, regional or national peculiarities of goods consumption in this social group (stratum) or in their entirety. These conclusions are fully applicable to consumer behavior management of young people, including those living in a metropolis. However, it should be borne in mind that consumer values and consumer preferences of youth in metropolises and youth living in geographically remote areas will have a significant and in some cases dramatic differences. This is due to the fact that young people in metropolises are at the epicenter of cultural, social and political life, availability of new technologically advanced products and services in this case is much higher than in geographically remote areas. That is why the consumer behavior of young people living in a metropolis is largely characterized by innovativeness (Dudin et al., 2014a), while youth in geographically remote from the center areas is characterized by more traditional consumer behavior. At the same time we must not forget that rapid development of information and communication technologies, as well as increase their accessibility to all segments of the population, allows us to predict that in the short medium term a type, a kind and a model of consumer behavior of young people living in geographically remote form the geographic center areas will be transformed and modified. It is important to understand that the main determinants that shape the specifics of consumer behavior of youth in metropolises, will evolve faster than the determinants that shape the specifics of consumer behavior of young people who live in geographically remote from the geographic center regions.

\section{References}

Baudrillard, J. (2000). In the shadow of the silent majority or the end of the social. Ekaterinburg: UGTU-UPI.

Berger, R. (2012). Strategy Consultants "Report on Chinese consumers, 2012". Official portal of "Vesti. Economy". Retrieved June 10, 2014, from http://www.vestifinance.ru/articles

Bogatyreva, A. A. (2011). Formation of fashion trends as a tool for regulation of consumer behavior. Terra Economicus.

Castells, M. (2007). Communication, power and counter-power in the network society. International Journal of Communication, 1, 238-266.

Chalmers, D. (2013). Conscious mind. In search of a fundamental theory. Moscow: Librokom.

Constantinescu, L., Goldbach, I., \& Gavrila, G. (2009). Culture-major determinant of the European consumer behavior. Annales Universitatis Apulensis Series Oeconomica, 11(2), 1019-1024.

Dudin, M. N., \& Lyasnikov, N. V. (2012). Socially oriented foresight as a tool for shaping of consumer behavior. European Journal of Economic Studies, 1(1).

Dudin, M. N., Ljasnikov, N. V., Kuznecov, A. V., \& Ju. Fedorova, I. (2013). Innovative Transformation and Transformational Potential of Socio-Economic Systems. Middle-East Journal of Scientific Research, 17(10), 1434-1437.

Dudin, M. N., Ljasnikov, N. V., Pankov, S. V., \& Sepiashvili, E. N. (2013). Innovative foresight as the method for management of strategic sustainable development of the business structures. World Applied Sciences Journal, 8(26), 1086-1089.

Dudin, M. N., Lyasnikov, N. V., Sekerin, V. D., Veselovsky, M. Y., \& Aleksakhina, V. G. (2014). The problem of forecasting and modeling of the innovative development of social economic systems and structures. Life Science Journal, 6(11), 535-538.

Filyurin, A. S. (2010). Russian regional features of branding. Marketing and market research in Russia, 5, 56-59.

Giddens, A. (1986). The Constitution of Society. Cambridge: Polity.

Habermas, J. (1971). Theorie der Gesellschaft oder Sozialtechnologie. Fr./M.

Ibrich, R. (n. d.). The new Japanese consumer. Insights \& Publications (McKinsey \& Co). Retrieved June 10, 2014, from http://www.mckinsey.com/insights/the_new_japanese_consumer 
Istratova, O. N., \& Eksakusto, T. V. (2012). Psychodiagnostics. Personal and professional qualities. Rostov-on-Don: Phoenix, 495.

Kovalchuk, M. A., \& Tarhanova, I. Y. (2005). Negative trends in the formation of youth subculture. Yaroslavl Pedagogical Herald.

Leibenstein, H. (1993). Bandwagon effect, snob effect and Veblen effect in the theory of consumer demand. The theory of consumer behavior and demand. St. Petersburg: Piter.

Luna, D., \& Gupta, S. (2001). An integrative framework for cross-cultural consumer behavior. International Marketing Review, 18(1), 45-69. http://dx.doi.org/10.1108/02651330110381998

Moscovici, S. (1998). Historical treatise on mass psychology. Moscow: Center of Psychology and Psychotherapy.

Petrovsky, A. V., \& Yaroshevskiy, M. G. (2010). Psychology; Dictionary (p. 494). Moscow: Nauka.

\section{Copyrights}

Copyright for this article is retained by the author(s), with first publication rights granted to the journal.

This is an open-access article distributed under the terms and conditions of the Creative Commons Attribution license (http://creativecommons.org/licenses/by/3.0/). 